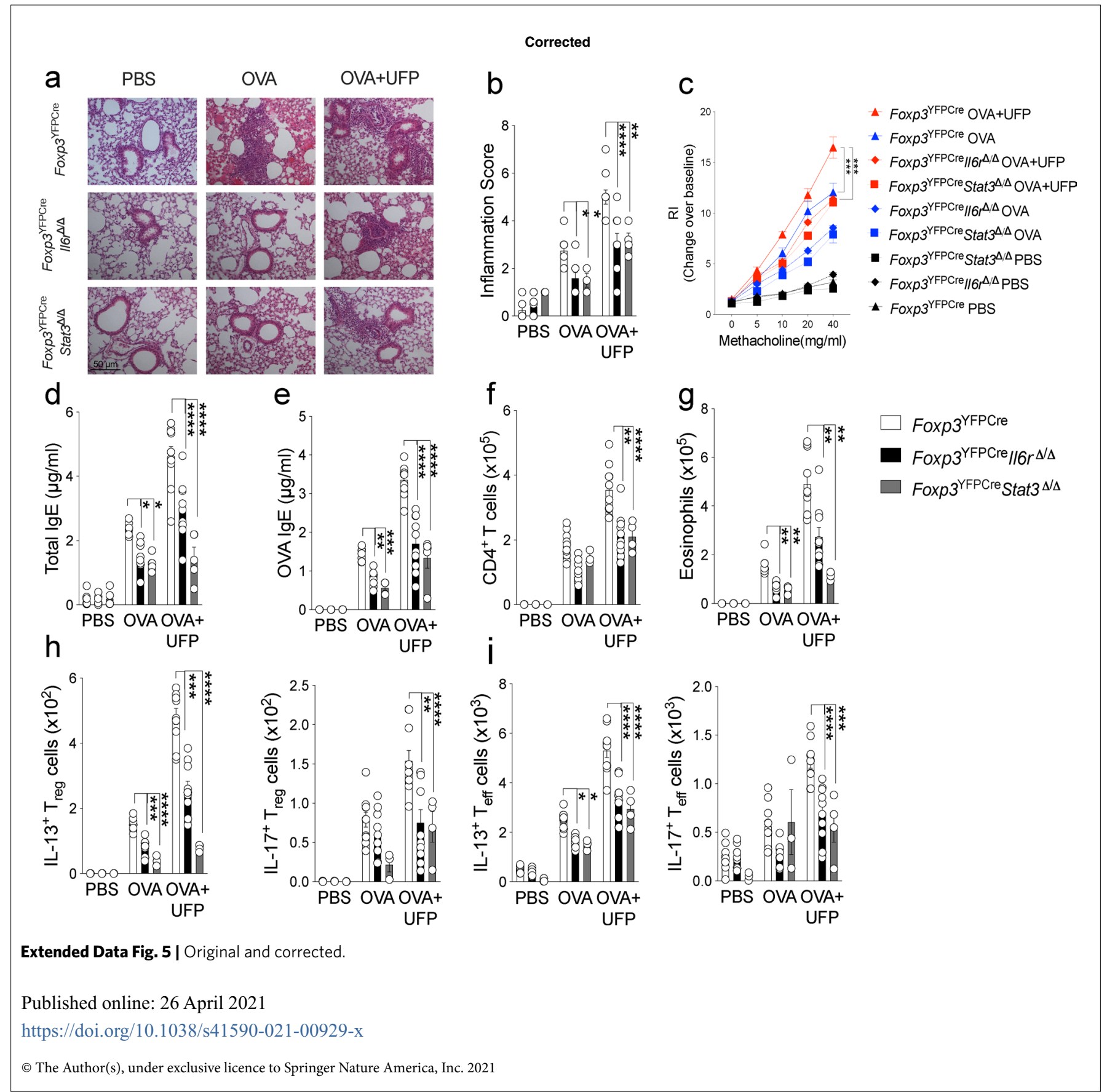

\title{
Publisher Correction: Fiber-poor Western diets fuel inflammation
}

Robert T. Patry and Cathryn R. Nagler (D)

Correction to: Nature Immunology https://doi.org/10.1038/s41590-021-00880-x, published online 11 February 2021.

In the corrected version of this article, in Fig. 1, the red and green arrows in the bottom panel were oriented incorrectly. The green arrow next to TNF, IFN- $\gamma$ and IL- 6 should be pointing up, and the red arrow next to IL-10 should be pointing down. The error has been corrected in the HTML and PDF versions of the article.

Published online: 26 April 2021

https://doi.org/10.1038/s41590-021-00932-2

๑) Springer Nature America, Inc. 2021 